\title{
Moldova: system survival vs. long-term viability
}

\begin{abstract}
One of the most important issues faced by the Moldovan government is the longterm reconciliation of two socio-economic objectives which seem to be apparently contradictory - efficiency and equity. Reasonable trade-offs could be found in order to reconcile the long-term desire to ensure the viability of the system with the shortterm imperative of guaranteeing the system's survival after the severe shock caused by the rampant economic crisis. This is especially evident in such fields as unemployment, education, social services and healthcare. There are two basic aims which must be targeted by the Moldovan government in order to lessen this tradeoff - social assistance system reform and pension system reform. The education and healthcare systems are strongly influenced by the practice of informal, out-ofpocket payments which reflect the inherent tendency of the entire system towards self-adjustment. These informal practices increase the general efficiency of the system but, at the same time, create additional perverse consequences which despoil it.
\end{abstract}

Keywords: poverty reduction, inequality, social assistance reform, unemployment, migration, youth unemployment, flexicurity, education reform, out-of-pocket payments, social justice, health care reform, health insurance

\section{Introduction}

Moldova has been an independent state since the collapse of the Soviet Union in 1991. As part of an ambitious reform effort adopted after independence, Moldova introduced a convertible currency, freed prices, stopped issuing preferential credits to state enterprises, backed land privatisation, removed export controls and liberalised interest rates. The government also entered into agreements with the World Bank and the IMF to promote growth and reduce poverty.

However, the reform process was accompanied by a prolonged recession and a drop in living standards for ordinary Moldovans as the shock from the break-up of the Soviet Union and the loss of centralised subsidies took effect. Complicating the economic picture was the forceful secession in 1990 of the eastern border region of Moldova, forming the separatist region of Transdniestr, which is not recognised internationally. Much of Moldovan industry, particularly steel, is located in the eastern part of the country, so the loss of control over Transdniestr meant that the country has been unable to exploit this industrial base. A lack of sound economic and social reforms, coupled with political instability in the first phase of the transition, has led to economic recession and increased poverty, thus qualifying Moldova as the poorest country in Europe.

Moldova's economy has been recovering in the years since 2000, mainly due to migrant remittances which currently represent about one-third of GDP. The remittances 
have increased the incomes of the population, raising aggregate demand and consumption. Consumption is satisfied largely by imported goods, with their more competitive prices and quality, dramatically increasing the trade and current account deficits.

Remittance-based economic growth was accompanied by a reduction of poverty, but the related population exodus has created disruption within the domestic labour market. The population declined by more than one-fifth during transition, while the emigration of almost one-quarter of the active population posed threats to the labour market. Thus, there has been a decrease in the economically active population and in the population employed within the economy (also by almost one-fifth), whereas the inactive population has dramatically increased.

At the moment, the Moldovan economy is recovering from the severe slowdown amidst the international financial crisis. Weak external demand is forcing a sharp contraction in industrial production, exports and inventories. Meanwhile, investment and household demand have been affected by the tightening credit conditions and the declining inflows of remittances from Moldovans working abroad.

The political crisis in the country, which emerged after parliamentary elections were held in April 2009, with the associated cuts in budget expenditures, represents a threat to a sharply-declining economy, obstructing the proper implementation of anti-crisis policies to support the private sector and vulnerable groups. The response to the economic crisis was late and incomplete, mainly due to the political situation.

The most recent parliamentary elections were held in Moldova on 5 April 2009. However, these were marred by post-election violence and allegations of fraud directed at the victorious Communist Party (PCM) by the opposition. Despite its success in the polls, the PCM fell short of the necessary 61 seats in the 101-seat parliament to elect a new president unopposed. The failure to achieve this figure in two consecutive votes meant that, in line with the constitution, fresh parliamentary elections had to be called.

These were held on 29 July 2009, under much international scrutiny. On this occasion, the four main opposition parties were able to gain enough seats to form a governing coalition, called the Alliance for European Integration (AEI). However, this coalition again lacked the necessary seats to elect its presidential candidate in the face of a PCM boycott. Fresh parliamentary elections were called once more, although amendments to the electoral law made by the AEI meant that these were not due until the latter half of 2010 or the first half of $2011 .{ }^{1}$

All these hardships have considerably impeded the process of increasing the living standards of ordinary Moldovan people and have created difficult dilemmas. One of the most important issues faced by Moldova's government refers to the long-term reconciliation of two socio-economic objectives which seem to be apparently contradictory - efficiency and equity. In being compelled to put the emphasis on efficiency, Moldova's government should not forget the need to preserve socially-acceptable discrepancies between different strata and to prevent undesirable protest movements which could result from the unrestrained interplay of market forces.

1 Editor's Note: the elections were held on 28 November 2010. 
Social policy in the Republic of Moldova from the point of view of the trade-off between efficiency and equity

Poverty is an acute social problem which affects the whole of society by bringing suffering to the people directly affected by it. At the same time, reasonable trade-offs may be found in order to reconcile the long-term desire to ensure the viability of the system with the short-term imperative of guaranteeing its survival after the severe shock of the rampant economic crisis.

In the first three years after independence, poverty registered the fastest rate of decline in Moldova, which reached the highest scores in Europe and Asia amongst countries in transition. Poverty reached a peak after the economic crisis in Russia in 1998 , when over $53 \%$ of the population were living on an income of less than $\$ 2.15$ per day. In 2000, the Moldovan economy returned to a positive trajectory, adjusted to the economic growth of the countries in the region and supported by incomes sent home by Moldovan emigrants, together with macroeconomic stabilisation. ${ }^{2}$ Absolute and extreme poverties decreased until 2004, but in 2005 they moderately increased; even so, the economic growth trend remained positive.

In spite of the economic growth trend in 2005 remaining the same as in previous years, this did not, however, have an impact on poverty reduction in the country, especially in rural areas where poverty rates kept going up. Thus, in 2005, the absolute poverty rate increased by $3 \%$, i.e. $29 \%$ of the population of the Republic of Moldova was below the absolute poverty threshold, while $16 \%$ were below the extreme poverty threshold. According to data from the National Bureau of Statistics, which was made public at the end of 2007, the total poverty threshold was MDL 747 in 2006, while the extreme poverty threshold was MDL 404; the total poverty rate was 30.2 per cent and the extreme poverty rate 4.5 per cent. Regretfully - and evidently - this data cannot be compared with the 2005 data owing to a change in the calculation methodology.

Other poverty measurement indexes register similar results. The depths of extreme and absolute poverties in 2005 were $4 \%$ and $8 \%$ respectively. That means that poor people had an average deficit of 11 lei before consumption reached the extreme poverty threshold, and 28 lei before it reached the absolute poverty threshold.

In 2005, the level of inequality in the Republic of Moldova registered a slight increase. This trend is reflected in the evolution of the Gini coefficient, which measures inequality in consumption between households at the country level: the higher the coefficient, the bigger the inequality. Hence, inequality, in terms of population consumption, remained at a relatively high level, the Gini coefficient being, in $2005-0.38$; in $2006-0.315$; and in $2007-0.298$. This highlights that the disparity of incomes between the rich and poor decreased in these years.

According to the Human Development Report for 2009, published by the United Nations Development Programme, Moldova was placed at 117 in 2009, six places lower than in 2008, alongside Guinea, Vietnam and Mongolia in the category of countries with a medium index of human development. 
Nevertheless, we can firmly assert that poverty predominates mostly in rural areas (34.1 per cent of households compared with 24.8 per cent in urban areas), while the poorest of all are:

- people living in large households (five and more persons), with a poverty rate of 39 per cent

- people living in households with three or more children, with a poverty rate of 48 per cent

- people living in households with three or more children, and with people of different generations, with a poverty rate of 35 per cent

- households consisting of farmers and pensioners, with a poverty rate of 42 per cent.

The residential environment is one of the factors which is most linked to poverty. The rural population makes up about $59 \%$ of the country's population, while nearly $66 \%$ of all poor people live in the countryside. Assessments of poverty rates according to area of residence show the same general profiles of poverty as in previous years, with significant differences between urban and rural areas. The population in big cities continues to run the lowest risk of living in poverty, with a rate of $20.6 \%$. In comparison with large cities, absolute poverty in rural areas is higher by 13.5 percentage points, while it is four points higher in comparison with small towns. The high distribution of poverty in rural areas is due to low agricultural production and a lack of opportunities for employment in other fields than agriculture.

The level of poverty grows with the number of members of households - from households with few members to those with five and more. The share of people living in large households (of five or more) in the total share of the population is nearly $22 \%$, while the share of all poor households is $34 \%$. The risk of poverty persists in households with one member $(9.6 \%)$; however, the share of single-person households in the total of population is just $7 \%$. The highest absolute poverty rates are registered in households formed of four members $-28.4 \%$; five members $-38.5 \%$; and six or more members $-55.9 \%$.

The poverty trend linked to the number of children remains the same as in previous years. The risk of poverty increases in line with higher numbers of children in families. Almost $67 \%$ of all households are families with a single child or none. These households are less poor, while the most affected are households with four or more children. The absolute poverty rate in these families is $65.4 \%$. Extreme poverty is also higher in these households, reaching a level of $14.8 \%$, or $10 \%$ higher than the average for the whole country. ${ }^{3}$

Analysis of the data by socio-economic group shows that the risk of poverty is higher amongst employees in the agricultural sector. The high poverty risk amongst farmers and those employed in agriculture is closely linked to the level of development of this sector. The agricultural sector of the Republic of Moldova continues to be considered as one which has the lowest levels of production and labour remuneration. Moreover, the substantial dependence of incomes on climatic conditions determines

3 Marcela Dilion (2009) 'Social concerns and responses to them' Early Warning Report No 1, August-December. 
their instability and represents an additional specific risk factor for poor rural households.

The increase in the ratio between the average incomes of the population and the main sources of that income (salaries, pensions), compared to minimum subsistence costs, is explained in that the incomes of the population increased within the period between the second quarter of 2008 and the second quarter of 2009 in circumstances of overall price stability. On some agricultural products, prices even declined.

One especially important factor in monitoring poverty is the share of the poorest quintile in national consumption.

This index represents the portion of total income/consumption which belongs to the poorest $20 \%$ of the population. The dispersal of household consumption expenditures by quintile is conducted in order to compare the consumption of poor and rich strata. In this respect, we notice a high polarisation of incomes in the Republic of Moldova.

The existing social assistance structure is based on a system of nominative compensation, which remains the most expensive social programme, making up $38 \%$ of all expenditure on social assistance in 2006. It has been recognised that this system has been inefficiently directed towards the people most in need. The system equally covers all income quintiles. A report drafted by the World Bank ${ }^{4}$ mentions that, in 2007, less than one-half of the population belonging to the two poorest quintiles $(40 \%)$ of the distribution of consumption expenditure received any of the available social help, making up less than $40 \%$ of the total value of social assistance. This means that more than $60 \%$ of social assistance payments are end up in medium and rich quintiles, thus making these payments regressive.

This situation limits the efforts at reducing poverty, playing as a constraint on the implementation of the reforms necessary for future economic development. The National Development Strategy for $2008-2011^{5}$ is the main internal document for strategic planning for the medium-term, outlining objectives for the development of the Republic of Moldova up to 2011 and stipulating the measures and actions by which those objectives may be attained. The Strategy serves as a single tool for the integration of the existing strategic framework and the correlation of the budgetary planning process (CCTM) with the policy framework, as well as providing the framework for technical and financial external assistance. In order to concentrate available resources on the implementation of these objectives and other measures with a high impact on the social and economic development of the country, the Strategy focuses on a limited number of strategic priorities. The fundamental objective is to create the conditions for the improvement of the quality of the population via a consolidation of the base for robust, lasting and inclusive economic growth. In the medium-term, i.e. up to 2011 , the government intended to make every effort to recover at least $7 \%$ of the disparity in incomes compared with the average in the EU and to reduce the absolute poverty rate to $24 \%$. The dependency of the poverty reduction process on economic growth was taken into consideration when fixing milestones. A poverty elasticity of -1.4 in respect to eco-

4 World Bank (2009) Moldova: Policy Notes for the Government May, available at: http://siteresources.worldbank.org/INTMOLDOVA/Resources/Moldova_Policy_Briefing_Book_eng.pdf

5 Law No. 295 from 21 December 2007. 
nomic growth was used, which was a regional average figure and relevant in the context of the Republic of Moldova.

GDP increased by $5 \%$ but, with applied simulations revealing that the poverty rate would reach nearly $21 \%$ by 2011 , the target was adjusted to take account of the nonlinear correlation between economic growth and poverty reduction. In the long-run, i.e. until 2015, the government will make efforts via the Strategy to recover at least $12 \%$ of the income disparity compared to the average figure in the EU, reducing the absolute poverty rate to $20 \%$.

Based on all of this, we could draw the conclusion that the Republic of Moldova is facing a series of problems leading to an increase in poverty, which may result in social protest:

- a slowed rate of economic growth

- a heightened disparity between the level of development in rural areas and in urban settlements

- the continuing growth in inequalities

- the dependence of the economy on climatic conditions, etc.

There has been a slight improvement in some social indicators, but the increase in the standard of living of the population is very slow. The 2009 drop in the economy makes more difficult the return of the incomes of the population to indicators similar to those which applied in the pre-crisis period. Such a conclusion comes from an analysis of the evolution of real per capita incomes, which identifies the consumption capacity of the population. A similar situation is present in the case of per capita incomes denominated in US dollars. In 2010, this indicator was expected to decline as a consequence of the depreciation of the national currency.

Compared to other countries, living standards in Moldova are the lowest in Europe. At $€ 46.29$ per month, the minimum gross wage in Moldova remains the lowest in Europe, being almost 34 times lower than that of employees in Luxembourg, which holds the top place in rankings conducted by the Federation of European Employers.

A relatively similar level to the minimum wage in Moldova is recorded in countries such as Montenegro (€55.00) and the Ukraine (€68.21). ${ }^{6}$ The structure of consumption expenditure also reveals that the population lives in poverty. In Europe, concerning living standards, Moldova is part of 'the group of losers', along with Serbia, Bosnia, Macedonia and Albania, followed at a significant distance by the Ukraine and Belarus.

A critical situation concerning poverty is also shown by the ratio of disposable income per capita to subsistence costs. According to this indicator, a citizen of Moldova is barely able to cover subsistence. The evolution of certain indicators regarding the social sector show a slight increase in 2010, but living standards in Moldova will remain unsatisfactory. A slight improvement in the situation is expected in the medium-term, but an evident improvement in living standards is likely to be possible only after achieving major economic improvement.

From the point of view of the trade-off between efficiency and equity, there are two major risks which affect social policy in Moldova. Before listing them, mention should

6 Depreciation of currency exchange rates in eastern Europe www.agenda.ro/imageseditions/1/1084_16541.pdf. 
be made that this trade-off has been aggravated seriously since 2009 due to the economic crisis. A substantial drop in budget revenues creates difficulties in expanding social programmes, the government being compelled to search for rapid short-term and medium-term solutions and to be much less prospective, frequently missing the longterm vision.

The social sector continues to have a high priority, the truth of this statement being confirmed by the increase in social expenditures in 2010 compared to 2009, this allowing a retention of the same share of GDP for this category of expenditure. Nevertheless, in order to find additional resources for development, the government has had to resort to measures with a negative social impact. Thus, the following has been provided to optimise personnel-related expenditure:

- a decrease in the number of staff in the budget sector by five per cent

- a decrease in staff expenditure on account of temporary inappropriate work leave by 2 per cent

- a decrease in the material aid provided to some categories of employees from two salaries per year to one salary per year.

These measures are not very popular and they reflect an attempt to increase the efficiency of the public sector, being at the same time concerned with the issue of equity, due to the additional revenues obtained by these means being re-allocated to the social sector. Mention should be made that the government has found a short-term compromise between efficiency and equity in providing a minimum level of social protection guaranteed by the state.

The problem of the long-term trade-off between efficiency and equity should be resolved by addressing two major issues of social policy in Moldova:

1. reform of the system of social assistance. The nominal compensation system is to be replaced by a system of social aid. Such a measure is a rational one: the nominal compensation system was not particularly efficient and this is mentioned in the National Development Strategy, approved in 2007:

The nominal compensation system is recognised as being directed inefficiently towards poor people. Its benefits cover equally all revenue quintiles.

The reasons for this inefficiency have already been discussed in this section and, in this respect, an efficient social assistance system will mean, at the same time, a more equitable one. The main purpose of such a new system will be to target those people who are most in need. Unfortunately, this is not the case in the current system.

2. the retirement system. There are several factors that raise question marks on the future of the national retirement system:

- population ageing

- a high degree of tax evasion, with respect to the effectiveness of the individual system of income tax, by the use of the practice of paying wages 'in an enve- 
lope', thus diminishing the basis for the collection of income for the national public budget (including the social insurance budget)

- the slow development of private pension funds.

Such a range of reasons puts significant pressure on the national public financial system. The state social insurance budget has previously faced situations in which it finished the budgetary year in deficit:

- in 2007, this amounted to MDL $87.4 \mathrm{~m}$

- in 2009, MDL $823.87 \mathrm{~m}$ were transferred from the state budget to cover the deficit in the state social insurance budget

- for 2010, the Law on the State Social Insurance Budget provides expressly for an amount of MDL $941.4 \mathrm{~m}$, which will be deployed as a transfer from the state budget to cover the deficit in the state social insurance budget. ${ }^{7}$

The reform of the pension system has become a necessity for the Republic of Moldova. Any postponement of the deep transformation of the pension system could generate serious constraints both as regards the public financial system and the social sector. In this direction, the solution of gradually increasing the age of retirement, as has been done in other eastern European states, should be considered as a possible way of reconciling efficiency and equity. Despite its unpopularity, this measure could lessen the burden on the state social insurance budget and provide the possibility of increasing the efficiency of the whole system.

\section{The trade-off between efficiency and equity in employment}

At present, the labour market is in the process of transformation arising from the transition to a market economy. The creation of a labour market requires additional work as regards the legal framework and certain economic structures. These factors make the process of the formation of the labour market both sustainable and less complicated.

The changes which occurred after the declaration of independence on 27 August 1991 led to:

- an increase in the number of the unemployed as a result of the contraction of all economic sectors

- an increase in the number of employees in the private sector and a decrease in those occupied in the public sector

- the passage from stable but badly-remunerated jobs to less stable but better-paid ones

- an increase in labour force migration.

The link between poverty and unemployment is well-known. In the Republic of Moldova, in addition, a strong link emerges between poverty on the one hand and unemployment and migration among young people on the other. The youth unemployment rate in Moldova is comparable with that in the European Union, but youngsters in Moldova suffer in an obvious way from the consequences of the existing disadvan-

7 Alexandru Fala (2010) 'Social Sector - Developments with inconclusive effects' Early Warning Report No. 2, January-April. 
tages on the labour market. There is a negative correlation between age and the risk of becoming unemployed.

Hence, people between 15 and 24 years of age face double the risk of becoming unemployed compared to people from the next age category up (25-34 years old). ${ }^{8}$ In the first quarter of 2009 , most unemployed young people had only high school education, which placed them in a disadvantageous position in the country. Indeed, the current economic crisis has badly affected unemployed young people. Again, in the first quarter of 2009, the unemployment rate amongst young people (i.e. those aged between 15 and 24 ) increased to $16 \%$ (compared to the trend in the past, which witnessed a decrease in the youth unemployment rate from $17 \%$ in 2006 to $14 \%$ in 2007). The unemployment rate amongst male young people (18\%) is higher than amongst women (14\%), even though the employed labour force is higher amongst men $(17 \%)$ than amongst women (15\%). The Q1 2009 youth unemployment rate was higher in rural areas ( $17 \%$; in urban areas: $15 \%)$. That is why it should be no surprise that migration in Moldova is rooted in rural areas and embraces mainly young people. Thus, the average age of migrants in 2006 was nearly 35 years old, while $37 \%$ were younger than thirty.

According to data offered by the National Bureau of Statistics, in 2009 Q2, the economically active population (both employed and the unemployed) in the Republic of Moldova was $1.36 \mathrm{~m}$ people, representing a decrease of $2.9 \%$ (or 41100 ) compared to the same quarter one year earlier. This change is due mainly to a decrease in the employed population (by 81400 people), especially among those employed in agriculture. The active population suffered as a result of this change: the share taken by the employed population decreased from $97.0 \%$ to $93.9 \%$, while the share of the unemployed rose from $3.0 \%$ to $6.1 \%$. No disparities were registered between the genders or on the basis of general location: the share of men $(51.1 \%)$ exceeded the share of women (48.9\%); while the share of the active population in rural areas was higher compared to the active population in urban ones (55.6\% and $44.4 \%$ respectively).

The active population aged 15 years and over was $45.9 \%$ of the total over- 15 population, a lower figure compared to the rate in the same quarter of the previous year $(47.5 \%)$. This index scored higher among the male population $-49.7 \%$ compared to $42.5 \%$ among females. Average occupation rates were $47.9 \%$ in urban areas and $44.5 \%$ in rural ones. In the $15-29$ age category, this index was $30.5 \%$, while in the group aged 15-64 (i.e. of the working age applicable in European Union countries, according to Eurostat methodology), it was $50.8 \%$, representing a decrease by $1.9 \%$ compared to the level of the second quarter of 2008 .

The employment rate of the population aged 15 years and older (as a percentage of the total population of the same age) was $43.1 \%$, a decrease by $3.0 \%$ compared to 2008 Q2. Men had a higher rate $(46.1 \%)$ than women $(40.4 \%)$. For residential areas, the employment rates were $44.0 \%$ in urban areas and $42.4 \%$ in rural ones. The employment rate of the population of working age in Moldova (16-56/61 years old) was $49.8 \%$; while it was $47.6 \%$ among the population aged $15-64$ years old; and $27.1 \%$ of those aged 15-29. 
According to the distribution of employed people by national economic sector, the number of people employed in agriculture was 412500 (taking a $32.3 \%$ share of the total employed population). Compared to 2008 Q2, the number of the population employed in agriculture significantly decreased - by $52600(11.3 \%)$, which means that every eighth person employed in agriculture left their job. In the meantime, every other person employed in agriculture continues to work on land belonging to the household.

In non-agricultural sectors, the number of employed people was nearly 863000 , lower by $28800(3.2 \%)$ on 2008 Q2. People employed in industry accounted for a $12.0 \%$ share (12.6\% in 2008), while construction took a further $5.7 \%(6.6 \%$ in 2008$)$. People employed in industry and construction registered $90.2 \%$ and $80.7 \%$ respectively of the prior year levels. The service sector took $49.9 \%$ of total employment, this share having increased by $3.4 \%$ on 2008 Q2. Mention should be made that not only the share but also the absolute number of people employed in the service sector increased compared to the same period in the previous year (by 5 100). By category of distribution, $69.8 \%$ of the population was employed in private enterprises; $25.7 \%$ in public enterprises; and $4.5 \%$ in enterprises which were either of a mixed category (i.e. both public and private) or else established with foreign capital. The pattern of the employed population, structured according to occupational status, shows that the number of public servants accounts for $67.2 \%$ of the total number.

Employment in the informal sector accounted for $12.1 \%$ of all employed people in the economy, while $30.7 \%$ had an informal job. Out of all employed people, public servants accounted for more than one-quarter $(27.4 \%)$, while nearly $12.5 \%$ of all public servants also had an informal job.

The number of unemployed people assessed according to the methodology of the International Labour Office was nearly 82 800, being 40300 up on 2008 Q2. Unemployment hits the male population hardest, accounting $60.9 \%$ of all unemployed people, as well as those living in urban areas, accounting for $57.9 \%$.

The unemployment rate (the share of ILO unemployed as a percentage of the entire active population) reached $6.1 \%$ on a country-wide basis, being higher than in the second quarter of 2008 (3.0\%). The unemployment rates for men and women were $7.3 \%$ and $4.9 \%$. Disparities were registered between unemployment rates in urban areas $(8.0 \%)$ and rural ones (4.6\%). Among young people (aged 15-24), the unemployment rate was as high as $15.4 \%$. In the $15-29$ age group, the unemployment rate was $11.1 \%$.

Recent forecasts for the labour market suggest an unprecedented rise in worldwide unemployment as a result of the crisis, increasing from 29 million people in 2007 to 59 million. In central and south-east Europe, as well as in the Commonwealth of Independent States (CIS), the forecasts predict an increase in unemployment of up to $35 \%$, while the number of employed people will decrease by between $1 \%$ and $2.8 \%$.

These assessments suggest that young people will be affected much more strongly; thus, the number of unemployed young people will expand by between eleven and seventeen million people worldwide in 2008-2009, representing an increase in the unemployment rate amongst young people of up to 14-15\%. Countries such as the Republic of Moldova, which have recently witnessed improvements in youth employment, now face a setback as a direct impact of the crisis. 
The main problem in Moldova is that old workplaces are not being replaced sufficiently quickly by more productive ones. The great lack of balance between the creation of new workplaces and those which are being closed down negatively affects employers' opportunities to pass from less productive jobs to more productive activities. The main factor establishing the slow rate of job creation is the high cost of launching a new business in Moldova. Red tape, corruption and high taxation are other reasons for reduced entrepreneurial activity. ${ }^{9}$

Another main dysfunction of the labour market is the disparity between the supply side of the education system and labour market needs and requirements. This is the explanation of the experts: a surplus (law, economy and foreign languages) on the one hand; accompanied on the other by an insufficiency of tailors, house painters, plasterers, welders, electricians, etc. Under such conditions, there is a mass migration of those whose absence is felt through the 'deficit' on the market.

In the Republic of Moldova, labour has not yet become a good, and its price is not at the level of cost although after 2000 there have been increases in the monthly average salary not only in the private but also in the budgetary sector. In accordance with the classification elaborated by the European Employers Federation (FedEE), which encompasses 48 European states, citizens of the Republic of Moldova are the most badlypaid. The gross minimum salary per hour is 3.27 lei (about $€ 0.20$ ), with a maximum amount of 336.43 lei/hour (about $€ 21.50$ ). The hourly salary is seventy times lower than that in Denmark, which ranks top of the classification.

Another characteristic of the labour market in the Republic of Moldova is the substantial lack of balance between the salaries of those with executive functions and those with lower positions. According to the FedEE study, this difference is greater than 100 , with workers receiving the lowest hourly salaries, while company presidents obtain the highest salaries.

The same FedEE data shows that those who work in international companies are $2.6 \%$ better paid than those who work for local firms. According to another classification made by FedEE, the minimum salary legislated for in the Republic of Moldova is the lowest minimum salary in Europe, accounting for $€ 29$ per month; while in Russia it is $€ 32$; $€ 59$ in Ukraine; and $€ 97$ in Romania. Given these conditions, the population is not motivated to work in Moldova, where the low salaries do not cover essential needs, let alone ensure a decent life. Thus, people prefer to work in other labour markets.

Another feature of the labour market is the existence of a significant section of people who are engaged in the informal economy. Labour supply exceeds demand, so many individuals accept work without an employment contract and that their job will not be subject to employment legislation and income tax. At the same time, they renounce social protection and certain benefits (notice in the case of dismissal, payments in the case of dismissal, annual paid leave, medical leave, etc.).

In conclusion, an attempt ought to be made to find an optimum ratio between the desired amount of labour market flexibility and the required level of social protection. The significant degree of social protection promoted by the state encourages employers to create an informal shadow economy which engulfs many workers. This means that 
the principle of efficiency overwhelms the norms of equity and that the regulations of the state are doomed to failure. At the same time, the low rate of job creation significantly impedes the process of labour market consolidation. That is why the official low rates of unemployment do not have much to say about the real state of affairs on the market. It could be said that, despite the substantial degree of worker protection, the efficiency criterion which prompts employees to circumvent official regulations is much stronger. Under these circumstances, officials should try to employ solutions such as flexicurity, which will provide an important degree of flexibility to those who hire workers.

\section{The trade-off between efficiency and equity in education}

Over the past fifteen years, the Moldovan education system has undergone a number of reforms intended to modernise and democratise education, as well as to establish appropriate conditions for making full use of each child's potential, regardless of the family's material standing, place of residence, ethnicity, spoken language or religious beliefs. The major intervention areas for reform were: the doctrine of the education system; the structure of the system; the written, taught and learned curricula; the concepts and methods of evaluation; and the management and financing of education. In this respect, the idea of equity was more important for officials in the $2000 \mathrm{~s}$, despite the processes of privatisation being much more influential in the 1990s and which resulted in the establishment of a multitude of private education institutions.

The further reformation of the education system, to ensure the right of every child to a quality education, implies an appropriate and truthful evaluation of education from the perspective of the requirements set out for child-friendly schools. Promoted at the international level, the concept of the child-friendly school focuses on five dimensions: inclusion and equity; efficiency of learning; the safety, protection and health of pupils; gender equality; and the involvement of pupils, families and communities in the life of the school. ${ }^{10}$

Education in the Republic of Moldova, including access to education, is indissolubly related to living standards. After 1990, the most affected social categories have been people employed in agriculture and in education. The long economic crisis, poverty, unemployment and corruption have deeply affected the quality of education. The most vulnerable families in the Republic of Moldova are families with children, since these are the ones most affected by poverty. The recent data on poverty are not at all encouraging and the situation continues to worsen.

Access to quality education in the existing conditions of the Republic of Moldova depends, in most cases, on the number of children in the family. The risk of poverty rises with an increase in the number of household members, from small households to those with five or more members, as was described above. It is important to mention in this context that families with children under 18 years of age, i.e. school-aged children, represent sixty per cent of the number of poor households but 52 per cent of all 
households, having a level of absolute poverty rate of 34 per cent, on average, with those in extreme poverty reaching 20 per cent.

Expenditure on education is the lowest of all expenditure categories (1.5 per cent); expenditure on foodstuffs takes the largest share (44.4 per cent). Rural inhabitants spend only 1.9 per cent of their total consumption expenditures on education, whereas the inhabitants of large towns spend 4.4 per cent and those of small towns spend 3.1 per cent.

At the same time, according to data provided by the Ministry of Economy and Trade, the volume of expenditures on education in 2006 varied significantly between quintiles and place of residence. Thus, wealthy families spend about four times more on these services than poor families, while people living in cities spend about 2.7 times more than people living in villages. If we focus our analysis on the expenditure patterns of families from the lowest quintile, it is evident that foodstuffs, housing and public utilities take the largest share of the family budget (about 73 per cent), with expenditure on education representing just 0.4 per cent. This data shows, once more, the limited possibilities of poor families to afford to keep their children within the education system.

Families with several children face the greatest difficulties. In addition to having many children to support, senior household members are also likely to lack well-paid jobs or adequate qualifications. A large number of these families live below the poverty line, in conditions that are harmful to child development.

The problems caused by poverty are aggravated by the education system of the Republic of Moldova having to face a critical lack of money over the past ten years. In 2009, the expenditure on education had increased, in absolute figures, by almost five times in comparison with 1997 but, in relation to Gross Domestic Product, they had decreased by about two percentage points. Still, even in these conditions, the share of expenditure on education in the general consolidated budget of the Republic of Moldova is comparable to the share allocated by the majority of European and central Asian states.

A detailed analysis by expenditure categories indicates that the financial resources allocated to education are used with a relatively low level of efficiency. The main causes of this phenomenon are these:

- imperfect school financing mechanisms, based on indicators centred on institutions and not on pupils

- imperfect mechanisms for the remuneration of teaching staff, based mainly on the seniority of staff and not on performance, leading to the exodus of young teaching staff from the education system

- the low wages of teaching staff, leading to the employment of teachers for 1.5-2.0 standard workloads, with immediate consequences for the quality of education

- a disproportionate distribution of financial resources via different expenditure categories, the share of expenditure that is not directly related to the teaching-learning process being exaggerated 
- a decrease in the number of pupils per teacher and in the number of students per non-teaching staff member

- a high share of non-teaching staff in the total number of employees in the education system.

Therefore, the financing system for education needs to be fundamentally streamlined, especially in primary and secondary education. This is directly related to the efficiency/equity dilemma. The new financing mechanism must be based on indicators related to pupils, in accordance with the principle of 'the money following the child'. This mechanism, which should be focused on efficiency, will also offer opportunities for public authorities to encourage school managers and education institutions to produce good results in ensuring access to education, including amongst pupils with special education requirements, and in improving the quality of the teaching-learning process. Obviously, school managers must also have possibilities to motivate teaching staff and, especially, to have a certain autonomy in establishing the wages of the wages of employees in their education institutions, depending on individual performance.

The shortage of finance is partially compensated for by contributions made by parents through informal payments. The IPP research study Informal Payments in PreUniversity Education and Equal Access to Education provides relevant data on the way schools currently try to settle issues related to the lack of financial resources.

Data collected from a representative sample consisting of parents, teachers and headteachers from December 2006 to February 2007 shows that the additional payments made by parents during one academic year amount to MDL 209m, which is 13.3 per cent of the financial means allocated by the state for the respective academic year. Parents pay for tutorials, additional lessons (in groups), the school fund, security services, repair works to classrooms and heating systems, exams, the processing of graduation certificates, gifts for teachers, school events and better marks for students. This means of co-financing creates problems for the equitable delivery of education services because many parents are unable to offer money for their children's education, which puts them in an extremely unfavourable position. ${ }^{11}$

At the same time, these additional contributions are vital for pupils' education. In the opinion of most parents, it is impossible for their children to obtain a quality education without contributions on their part. One in seven teachers and headteachers support the opinion of the parents. Many parents (48.6 per cent) say that teachers dedicate more time and effort to children whose parents contribute more to the school's needs. At the same time, parents and a number of teachers themselves acknowledge that, under these conditions, some pupils from poor families are disadvantaged and do not receive the attention of the teacher because their parents cannot afford additional payments to the school: this was quoted by almost one-half of interviewed parents (49.9 per cent) and some teachers and headteachers (12.6 per cent and 16.7 per cent, respectively). In some cases, a child's dignity is also affected when his or her parents cannot manage to make the required payments.

The negative impact of informal payments on the education process is recognised by 35 per cent of parents and 25 per cent each of teachers and headteachers. At the

\section{1 ibid.}


same time, 80-90 per cent of teachers and headteachers deny that pupils from poor families are less privileged, whereas 50 per cent of parents affirm the contrary.

The relatively low wages of teaching staff force them to wait for, and even ask for, money from parents. Obviously, the attitude of teaching staff and parents with respect to this phenomenon varies, but parents, teachers and headteachers think that this is adverse to a child-friendly atmosphere.

Thus, we may ascertain that the complicated economic situation in the Republic of Moldova, coupled with inappropriate attitudes towards education expressed through decisions that limit the education budget, have created conditions within the education system that are negatively influencing the education process and limiting the access of children from under-privileged families to quality education. The principle of shortterm efficiency is taking precedence over any other norm and idea, and this is grossly disfavouring the state objective of equality of opportunity as a means of contributing to unrestrained human development in Moldova.

\section{The trade-off between efficiency and equity in the healthcare system}

The Moldovan healthcare system aims to provide the entire population with universal access to a basic package of healthcare services. Previous state guarantees for universal access to the full range of healthcare services free at the point of use has proven to be unsustainable in the economic climate of post-Soviet Moldova. The reality was that the state declaration of universal access was not implemented, with access being severely restricted by the practice of informal out-of-pocket payments.

Consequently, these commitments have been substantially revised and have been substituted by a more limited universal package with a clearly-defined parcel of services covered by mandatory social health insurance. In the first year following the introduction of social health insurance, this pragmatic approach succeeded in extending the accessibility of healthcare services free at the point of use to the population, although this is not yet universal. There is already growing political pressure to widen the state guarantees, although it is not clear that this is economically sustainable at this stage.

Equity is a key performance measure for a health system. Payments for health services should be progressive, with richer households paying proportionally more towards financing the system than poorer households; as well as being horizontally equitable, with households of the same ability to pay making an equal contribution.

However, the consistently high levels of out-of-pocket payments in the financing of healthcare in Moldova has meant that the poorest households have had more limited access and have had to pay out a much higher percentage of their income. Average outof-pocket expenditure when it came to hospitalisation was more than three times average household expenditure, so the poorest households bore a potentially catastrophic financial risk where ill-health required hospitalisation. Results from a UNICEF survey in 1997 found that nearly $50 \%$ of people requiring hospital services financed out-ofpocket payments by selling assets or incurring debt. ${ }^{12}$ Unofficial user fees and the need 
to pay full cost for pharmaceuticals were essentially universal phenomena so, alternatively, the poor simply forewent healthcare because of resource constraints.

By the end of the 1990s, when the healthcare financing crisis was at its peak, the poorest sections of Moldovan society were paying a significantly higher proportion of their household budget on accessing care, which reflected the disastrous inequities in the system. Against this background, the need to develop a financial risk-pooling mechanism to mitigate risk among the poorest populations became compelling. ${ }^{13}$

The introduction of mandatory social health insurance has helped to protect the population from the financial risks associated with ill-health. For example, in 2004, the average direct household expenditure on health for the poorest $20 \%$ of the population fell $21 \%$ in real terms compared with $2003 .{ }^{14}$ Also, the share of out-of-pocket payments on health fell from $51.5 \%$ in 2003 to $42.3 \%$ in 2005, for both official and unofficial payments. This was achieved because the government undertook to pay the contributions of certain groups, and these contributions are meaningful as they relate to the actual cost of care and are linked to employee contributions.

Nevertheless, even though the magnitude of out-of-pocket payments has decreased owing to the recent reforms, out-of-pocket payments for health are still relatively high for the European region as a whole. ${ }^{15}$ Research into the cost of hospitalisation has also shown that health insurance effectively provides financial protection to insured families; on average, the costs of hospitalisation are $83 \%$ higher for an uninsured person. ${ }^{16}$

However, while the poorest households are now spending less on health care, the utilisation of health services by the poorest households has also fallen. ${ }^{17}$ Also, the high out-of-pocket cost of pharmaceuticals is eroding financial protection for the poor. ${ }^{18}$

Regional differences in per capita funding for healthcare have decreased following the re-centralisation of resource pooling but, despite ample coverage of health facilities, the more remote regions are still served inadequately and the rural poor are less likely to gain access to services. Poor rural households are also those that are least likely to have insurance and, consequently, are the ones most likely to have to pay for treatment and consultations. Rural services are also the ones which are most acutely understaffed.

Consequently, it can be said that the current system of health financing does not ensure the effective protection of the whole of the population from financial risks, even though the recent reforms have had a very positive impact on equity concerning the costs and benefits of the healthcare system overall. Out-of-pocket payments are still high and a sizable proportion of the population (20-25\%) is not covered by social health insurance; many of these people belong to the country's poorest households. ${ }^{19}$

13 Dina Balabanova (2007) Health Sector Reform and Equity in Transition July.

14 Government of the Republic of Moldova and World Band (2006) Health policy note Chişinău: Government of the Republic of Moldova and World Bank.

15 WHO Regional Office for Europe (2007) Concepts and principles for tackling social inequities in health WHO: Copenhagen.

16 Government of the Republic of Moldova and World Bank (2006) op. cit.

17 ibid. and S. Shishkin, G. Kacevicius and M. Cocianu (2006) Evaluation of health financing reform in the Republic of Moldova WHO Regional Office for Europe: Copenhagen.

18 Government of the Republic of Moldova and World Bank (2006) op. cit. ibid. 
The result is that households with higher incomes are benefiting more from health services than are those with lower incomes. However, the Moldovan government has undertaken to address these inequities and to support social solidarity in the national health policy.

In the Soviet era, the level of revenue that a facility received was dependent on the number of officially-registered beds and the number of staff employed. Performance, in terms of the productivity of facilities, the quality of care and patient satisfaction, was not considered in the funding equation. This led to inappropriate incentives to retain unnecessary beds; to admit patients with little or no need for hospital care, and to keep these patients hospitalised for as long as possible; and to invest little in improving the quality, appropriateness or efficiency of their care. Moreover, as resource allocations were made on the basis of capacity rather than health need, the bulk of public resources went to urban centres, where the largest number of health facilities was located.

These Soviet legacies determine the nature of the inefficiencies in the post-Soviet Moldovan healthcare system. Efficiency in Moldova has been limited by an excessive and inefficient infrastructure; a limited use of appropriate clinical protocols; and a lack of capacity in the primary healthcare system.

Profound hospital restructuring took place after the financial crisis, when much of the excess capacity in the Moldovan healthcare system was reduced. In just one year, 1998-1999, the number of hospitals fell from 276 to 150; while between 1991 and 2006 the hospital stock was reduced by $75 \%$ : in 2006, there remained just 84 hospitals in Moldova. ${ }^{20}$

However, much of the consolidation meant the closure of rural hospitals, while secondary care hospitals in Chişinău, i.e. the republic-level specialist hospitals, were broadly unaffected. Consequently, the hospital sector still absorbs a significant amount of funding relative to primary care, despite concerted reform efforts to change resource allocation mechanisms. However, this may well change now that family medicine centres are no longer integrated into other local health services under the management of rayon (county) chief doctors.

The parallel health systems under the control of other ministries are also a source of great inefficiency in the system, and there is currently no strategy for consolidating or restructuring those facilities that have remained outside the programme of reform. The focus on developing primary health care, and the substantial investment in the training and retraining of personnel, as well as the reallocation of resources away from in-patient care, has served to build capacity in the primary healthcare system which, historically, had been extremely weak. However, problems still remain with attracting and retaining staff to work in primary care, particularly in rural areas. The development of health technology assessments and the introduction of evidence-based medicine remain key concerns in reforming the Moldovan healthcare system, both in terms of ensuring the efficient use of resources and in terms of improving the quality of care.

Common to other countries in the CIS, there is a need in Moldova to improve the quality of healthcare services not only through the implementation of evidence-based approaches to clinical decision-making but also through improving the incentives for 
service providers to comply with standards of good practice. To achieve improvements in the quality of care, there is a need to strengthen the stewardship role of the Ministry of Health in policy-making and evaluation, as well as in the regulation and monitoring of the system.

It is also important that the effective strengthening of primary care continues. This requires continued shifts in resource allocation away from in-patient care so that ambulatory health centres are resourced and empowered to deal with the vast majority of the population's healthcare needs which can, indeed, be met at the primary healthcare level. There is also a need to increase the efficiency of the system and to ensure that the system of the financing of health has appropriate incentives for healthcare providers. For example, the current hospital payment system provides republican hospitals with an incentive to treat simple, non-complex cases because they are paid more for this than would a rayon hospital, which could treat the same patient equally well. Hence, the 'profit margin' (the difference between reimbursement and average case cost) is greater for republican hospitals and they are discouraged from treating more 'expensive', complex cases - that is, those that republic-level hospitals are designed to treat.

The central lesson to be learned from the Moldovan experience of introducing mandatory social health insurance is that this can be highly effective where it is introduced as a means of initiating root-and-branch reforms of the system via the use of contracting as a mechanism to improve accountability, transparency and quality, even though mandatory social health insurance does not necessarily provide universal access or coverage. The introduction of mandatory social health insurance in Moldova has improved the transparency of the system and reduced the magnitude of informal payments. Approximately $30 \%$ of respondents in a household survey conducted in 2005 mentioned that the practice of informal payments had completely or partially disappeared once social health insurance was introduced, although $52.9 \%$ of respondents did mention that it had not disappeared altogether.

Nevertheless, this same survey also showed that the level of information the general population has about health insurance, their understanding of the benefit package and their acceptance of reform and level of satisfaction with it, was very low. Inequality in access, benefits and outcomes are the key challenges which must be addressed in future healthcare reforms, while improving the population's knowledge of the social health insurance system and its credibility are major tasks associated with this challenge. The population needs to be informed more adequately about the nature of the reforms and the reasons for them, as well as their rights and the expected benefits.

There is also growing concern about the distance between policy-makers and the practitioners who are at the forefront of reform initiatives, yet without always being included in and informed of the reasons for change. ${ }^{21}$ Experience from many countries confirms the importance of adopting a systemic approach to reform and combining bottom-up and top-down approaches, with simultaneous developments at both policy and operational levels to create shared ownership, to reduce resistance and to enable lesson-sharing at different levels of the health system. However, for this to occur there needs to be adequate and appropriate management capacity at these levels. Manage- 
ment capacity in the Ministry of Health and the National Health Insurance Company, and at healthcare provider levels in Moldova, needs to be substantially augmented to facilitate the implementation of the planned reforms and to improve planning and management functions in the health system.

Nevertheless, the need to achieve greater coverage in the social health insurance system is acute and well-recognised by the Moldovan government. Disparities in health insurance coverage have both socio-economic and geographical dimensions, with coverage lower in rural areas than in urban ones, and with poor or extremely poor households most at risk of being uninsured.

The most vulnerable would appear to be the rural poor and extremely poor households, as these are the only groups that appear to have been adversely affected by the introduction of mandatory social health insurance, with utilisation rates actually falling in $2004 .^{22}$ Drug costs are a major contributor to the lack of financial protection in the system and, therefore, the drug benefit package should be carefully expanded. There is, however, a very real need to resist the populist extension of healthcare guarantees that are unsustainable. These would, in fact, promote informal payments in the system and threaten equity while undermining the credibility of the new system.

\section{Conclusions}

This article has sought to unveil the possible trade-offs between efficiency and equity in different areas of social policy in Moldova. The topic of analysis was the possible reconciliation of equity and efficiency in social and employment policies, education and healthcare. The idea was to discover those policy situations that promote greater equity but have little effect on efficiency or - even better - those policy situations where equity and efficiency complement each other and where government policies, mostly transfers from richer to poorer individuals, may even potentially produce a more efficient society than would occur in the absence of those activities.

In employment and social policies, we could say that Moldova is, on the whole, moving towards the policies carried out in Europe at large. The scope for equity is being narrowed and is considered mostly in the context of the implementation of more stringent conditions and a stronger emphasis on active measures in employment policy, with unemployment benefits being linked more directly to participation in training and reskilling programmes. The same is true for education, healthcare and other social policies. We could refer to a sort of state disengagement in this field due to the more liberal approach which emphasises efficiency to the detriment of equity. In these circumstances, it is important not to let social policies be overwhelmed by market forces; this could create both severe inequalities, increasing the gap between poor and rich people, as well as protest movements which could disrupt the social equilibrium.

The education and healthcare systems are strongly influenced by the informal practices of out-of-pocket payments, which reflect the entire system's inherent tendency towards self-adjustment. In order to avoid the extremely inefficient conventions of the exclusive state financing of these branches, which establish the vicious practice of the permanently inadequate provision of resources, these branches tend to attract additional 
financial support from unusual sources. Such informal practices increase the general efficiency of the system but, at the same time, create additional perverse consequences which despoil it. This self-adjustment generates gross inequalities and creates marginalised people with very limited access to the services provided.

The trade-off between efficiency and equity has been seriously aggravated since 2009 as a result of the economic crisis. A substantial drop in budget revenues has created difficulties in the expansion of social programmes, the government being compelled to search for rapid short-term and medium-term solutions which lead to it being less focused on the long-term vision. The social sector continues to have a high priority, which was confirmed by the increase in social expenditure in 2010 in comparison with 2009 , permitting the retention of the same share of GDP for this category of expenditure. We should be aware that these solutions are temporary and, in the long-run, that they must be supplemented by more sustainable reforms which could include the reform of the pension system, the introduction of flexicurity in the labour market or the optimisation of the schools system by the establishment of an optimal ratio for their financing. The adoption of these measures depends on the ability of state agencies to undertake ambitious efforts in order to create a more equitable society, but not at the expense of efficiency.

\section{References}

Balabanova, Dina (2007) 'Health Sector Reform and Equity in Transition' July.

Dilion, Marcela (2009) 'Social concerns and responses to them' Early Warning Report No 1, August-December.

Fala, Alexandru (2010) 'Social Sector-Developments with inconclusive effects' Early Warning Report No 2, January-April.

Government of the Republic of Moldova and World Band (2006) Health policy note Chişinău: Government of the Republic of Moldova and World Bank.

International Monetary Fund (2007) Republic of Moldova. First review under the threeyear arrangement under the poverty reduction and growth facility and requests for waiver of performance criterion and augmentation of access.

IPP (2009) Baseline study on basic education in the Republic of Moldova from the perspective of child-friendly schools.

Ministry of Finance (2008) Laws on the State Budget for 2005, 2006, 2007 and 2008.

National Scientific and Applied Centre for Preventive Medicine of the Ministry of Health and Social Protection, ORC Macro (2006) Moldova demographic and health survey 2005.

Orlova, N and P. Ronnas (1999) 'The crippling cost of an incomplete transformation: the case of Moldova' Post-Communist Economies 11(3): 373-397.

Platis, M (2008) Economia sectorului public, Eficiența şi echitatea sistemelor economice. 
Shishkin, S, G. Kacevicius and M. Cocianu (2006) Evaluation of health financing reform in the Republic of Moldova WHO Regional Office for Europe: Copenhagen.

Tatarciuc, A (2007) Labour Market in Moldova: Falling Apart IDIS Viitorul.

World Bank (2009) Moldova: Policy Notes for the Government May, available at: http://siteresources.worldbank.org/INTMOLDOVA/Resources/Moldova_Policy_Briefing_Book_eng.pdf

WHO Regional Office for Europe (2007) Concepts and principles for tackling social inequities in health WHO Regional Office for Europe: Copenhagen.

'National Concept on Child and Family Protection' Official Newspaper of the Republic of Moldova No. 17, Article 121, 31 January 2002.

'The Law on Ensuring Equal Opportunities for Men and Women' Official Newspaper of the Republic of Moldova No. 047, Article 200, 24 March 2006.

'The National Development Strategy for 2008-2011' Official Newspaper of the Republic of Moldova No. 18-20, Article 57, 29 January 2008. 